\title{
EL DOWN JONES DE LA BOLSA DE NUEVA YORK
}

Dr, LADISLAO SAAVEDRA RASSO

\section{SÍNTESIS}

Trata sobre el Índice Bursátil Mundial.Down Jones:

- Su origen

- Composición y

- Fluctuaciones en sus 103 años de existencia

\section{EL DOWN JONES: ÍNDICE DE LA BOLSA DE NUEVA YORK}

Es un indicador de la marcha de las cotizaciones en la Bolsa Norteamericana. Por su antigüedad y representatividad es aún el más importante.

Sobre el particular, Joel Popkin, economista de Washington, dice: "La gente cree que el Down Jones es un indicador de cómo va la economía estadounidense, pero en realidad es un índice de cómo va la economía mundial".

\section{Breve reseña histórica}

Este promedio Down Jones se publicó por primera vez el 26 de mayo de 1896 en el Customer's Afternoon Letter (el precursor de The Wall Street Journal).

Charles H. Down concibió su indicador en un momento crítico para la economía norteamericana, ya que una ola de fusiones modificaba profundamente el panorama empresarial estadounidense y en un sector tras otro, las grandes empresas buscaban la creación de mercados nacionales y con frecuencia monopolios.

Down pronosticó que estas compañías constituían "El gran mercado especulativodel futuro".

Estas firmas recién creadas incluían, entre otros, los sectores del:

$\begin{array}{ll}\text { Cobre } & \text { Pegamento } \\ \text { Heno } & \text { Agujas de coser } \\ \text { Harina } & \text { Azúcar } \\ \text { Plomo } & \text { Whisky } \\ \text { Cristal plano } & \text { Clavos } \\ \text { Carbón } & \text { Acero }\end{array}$

Sin embargo, muy pocos reconocieron la tendencia, ya que para la mayoría de los estadounidenses, los negocios todavía eran una actividad local: la fundición, la tienda del barrio, la granja. La economía nacional parecía algo abstracto.

En 1899 Charles H. Down y su socio Edward Jones, integrantes de la Down Jones y Cía., lanzaron The Wall Street Journal, donde Down desempeñaba el cargo de director.

\section{Cambios en componentes del promedio industrial}

El índice original de 12 acciones industriales del Down es actualmente de 30 representativas de todo el mercado y la industria norteamericana. El único sobreviviente es la de General Electric. 
En marzo de 1997, Down Jones Cía. reemplazó a tres de las compañías que formaban parte del promedio, con el fin de elevar la representación de los sectores:

- Tecnológico

- Financieroy

- De atención médica

La medida constituyó uno de los cambios más importantes en la historia de este indice bursátil.

Los reemplazos enunciados fueron:

- Travelers Group por Westinghouse Electric.

- Hewlett - Packard por Texaco Inc.

- Johnson and Johnson por Bethlehem Steel Corp. y

- Wal.Mart Store porWoolworth Corp.

Principales récords e hitos del Down Jones:

- $\quad$ El índice original comenzó con 40.94 puntos.

- El 12 de enero de 1906 cierra, por primera vez, por encima de los 100 puntos.

- $\quad$ El 12 de marzo de 1956 cierra con 500.24; es decir, encima de los 500 puntos por primera vez.

- $\quad$ El 14 de noviembre de 1972 superó la barrera de $1.000(1.003 .16)$.

- El 08 de enero de 1987 superó la barrera de los 2.000 (2.000.225).

- El 17 de abril de 1991 superó por primera vez la barrera de los 3.000 .

- El 14 de octubre de 1996 el Down Jones llegó a los 6.000 puntos.
- $\quad$ En febrero de 1997 superó los 7.000 y el 16 de julio llegó a 8.000

- $\quad$ El 06 de abril de 1998 el Down Jones cierra por encima de los 9.000 puntos.

- En 1998 la crisis financiera asiática y los problemas de Rusia originaron una caída hasta los 7.500 puntos.

- $\quad$ El 16 de marzo de 1999 supera por primera vez la barrera de los 10.000 puntos durante "escasos segundos". Ocurrió a las 09h50 hora local ( 1 r.50 GMT) al ganar 41.35 puntos y llegar hasta los 10.001 .12 para retroceder posteriormente.

\section{El Down Jones sobre los 10.000 Puntos}

Por primera vez en la historia, el promedio industrial Down Jones cerró por encima de 10.000 puntos (el 29 de marzo de 1999). Alcanzó la cifra de 10.0006.78.

Al pasar esta barrera, el Down Jones queda por encima en un $300 \%$ de su nivel de octubre de 1990, año en que comenzó la actual bonanza. Este promedio creció 13 veces desde 1982.

En los 103 años de historia del Down, hasta el 30 de marzo de 1999, nunca se había registrado un periodo positivo tan largo en el mercado de valores de los Estados Unidos. Apenas se sabe de uno igual de poderoso, el que terminó en 1929.

Nunca antes habían participado tantos estadounidenses en el mercado, ya sea directamente con operaciones en acciones o indirectamente a través de Fondos Mutuos; tampoco tiene precedente la cantidad de riqueza vinculada a las acciones. 
El impacto en las bolsas

latinomericanas

Según los analistas, el promedio del Down Jones arriba de los 10.000 puntos, no significa mucho. Lo importante no es tanto el récord histórico sino la tendencia creciente del mercado.

El efecto ideal para las bolsas latinoamericanas sería que los inversionistas decidieran que las acciones estadounidenses ya han subido bastante y que es hora de buscar otros mercados; pero Davis Chong, estratega latinoamericano para el Banco de Inversión Bear Stearns, piensa que "quizás sea pedir demasiado".

\section{¿Cuál será la tendencia Futura?}

El tercer récord consecutivo que alcanzó el Down Jones fue en los últimos días de mayo de 1999, cuando cerró con una alza de 32.93 puntos equivalentes a un $0.30 \%$ (a 10.878 puntos) .

Sin embargo, el 27 de mayo de 1999 (fecha de cierre de este artículo) el promedio sufrió un tropezón histórico, cayó 235.23 puntos ó un $2.20 \%$ y quedó en 10.446 .93 unidades.

La interrogante es: ¿Cuál será la tendencia futura?

Considerando lo manifestado por MANLEY: de SALOMON SMITH BARNEY:

- "En los 80, el motor del mercado era la ambición".

- "En los 90, es el miedo".

\section{FUENTE}

Publicaciones The Wall Street Journal Americas - El Comercio Lima - Perú. 